\title{
Antenna Azimuth Position Control System using PID Controller \& State-Feedback Controller Approach
}

\author{
Aveen Uthman ${ }^{1}$, Shahdan Sudin ${ }^{2}$ \\ ${ }^{1}$ Departement of Communication Engineering, Sulaimani Polytechnics University, Iraq \\ ${ }^{2}$ Faculty of Electrical Engineering, Universiti Teknologi Malaysia, Malaysia
}

\begin{tabular}{l} 
Article Info \\
\hline Article history: \\
Received Jan 9, 2018 \\
Revised Mar 20, 2018 \\
Accepted Mar 28, 2018 \\
\hline
\end{tabular}

Keyword:

Azimuth position control system response MATLAB simulation PID controlle

Pole placement State-feedback controller Zeglior-tunung method

\begin{abstract}
This paper analyzed two controllers with the view to improve the overall control of an antenna azimuth position. Frequency ranges were utilized for the PID controller in the system; while Ziegler-Nichols was used to tune the PID parameter gains. A state feedback controller was formulated from the state-space equation and pole-placements were adopted to ensure the model design complied with the specifications to meet transient response. MATLAB Simulink platform was used for the system simulation. The system response for both the two controllers were analyzed and compared to ascertain the best controller with best azimuth positioning for the antenna. It was observed that state-feedback controller provided the best azimuth positioning control with a little settling time, some value of overshoot and no steady-state error is detected.
\end{abstract}

Copyright $@ 2018$ Institute of Advanced Engineering and Science. All rights reserved.

Corresponding Author:

Aveen Utman,

Departement of Electrical and Computer Engineering,

Sulaimani Polytechnics University SPU,

Sulaimaniyah, Kurdistan Region, Iraq.

Email: aveen.hassan@spu.edu.iq

\section{INTRODUCTION}

The issue of antenna azimuth position control has become one of the many aspects that have drawn the attention of researchers in the control of antenna placement [1]. These interests are due to the major roles and enhance performances that would be derived from correct azimuth positioning of an antenna. Several techniques were proposed to achieve an optimum control of the azimuth position but such positioning remains a control challenging problem.

Hoi et al [2] conducted a research on satellite tracking using fuzzy proportional integral derivative PID control techniques and the conventional PID controller to get the best in performance on satellite tracking. Both the step response in the two techniques presented evidence of chattering phenomena which may lead to poor and weak result and conclusion respectively. Xuan et al [3] introduced a discrete control system using PID controller to achieve a better control on satellite antenna angle deviation. The shortcoming of this work is lack of proper tuning of the PID gains for precise results. Soltana et al [4] considered the case of overseas satellite telecommunication where the control system was applied to an on-board motorized antenna; the separate controller was designed to detect a fault in the satellite control. Though the controller was not robust enough to enable handle the detected fault in the controlled signal. The research of [5] and that of [6] is basically using PID and Linear Quadratic Gaussian (LQG) for the antenna azimuth position control system; both researchers were faced with similar shortcomings of degraded performance due to system nonlinearities and delay in reaching setpoint. A much better settling time and less overshoot were achieved by [7] where the Fuzzy logic controller (FLC) and a self-tuning fuzzy logic controller (STFLC) was utilized in the design but chattering phenomena were reported as the setback. All these make the antenna 
azimuth positioning a challenging control problem. There is need for a high-performance controller; hence the motivation of this paper is to come up with a better solution to the mentioned problems.

In this paper, the concept of PID and feedback controller will be presented to handle the issues related to the antenna azimuth positioning as well as to prevent the said lapses experienced in literature. The two controllers will be compared to enable justify the best controller with high azimuth positioning with less possible positioning, overshoot settling time and chattering. Section 2 of this paper describes the mathematical modeling of the proposed controllers. An analysis on the controllers is shown in Section 3. Section 4 concludes with the obtained results.

\section{MODELING OF THE SYSTEM}

Two potentiometers are included in aforementioned system for controlling the position of telescope antenna; one is utilized at input and one at output as transducer, a power amplifier, a preamplifier, a load and a motor. The overall system includes 5 subsystems, and each subsystem has a related transfer function. A more detailed of provided schematic diagram is shown in Figure 1. As well as, Figure 2 represents the system block diagram for controlling the position of antenna azimuth.

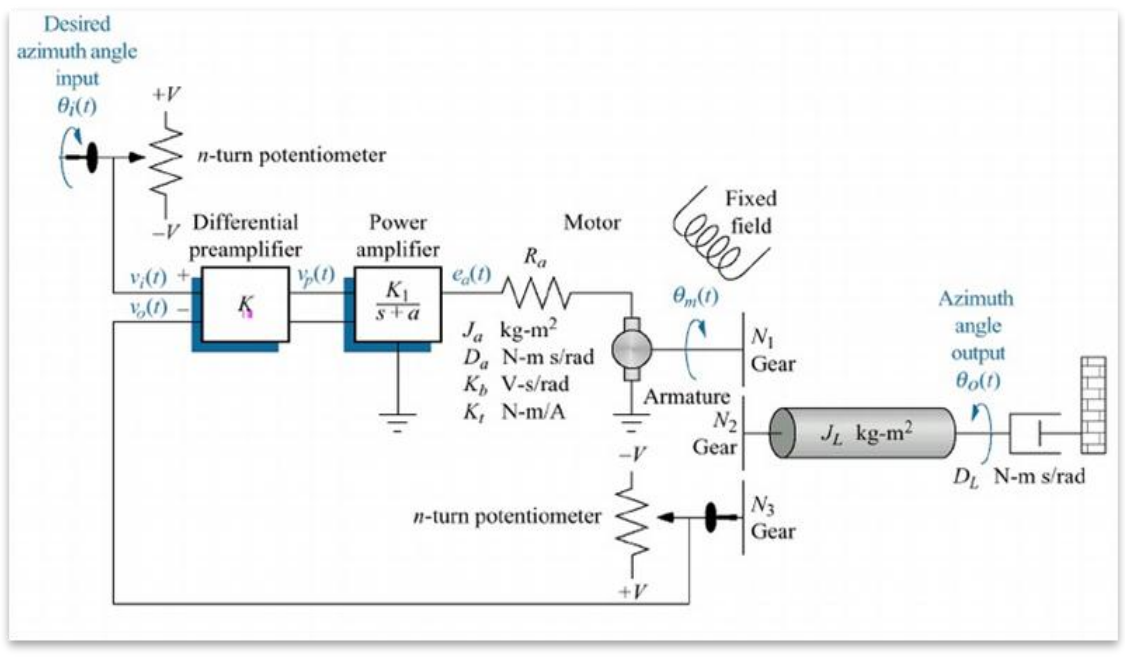

Figure 1. Schematic diagram of antenna-azimuth position controlling system

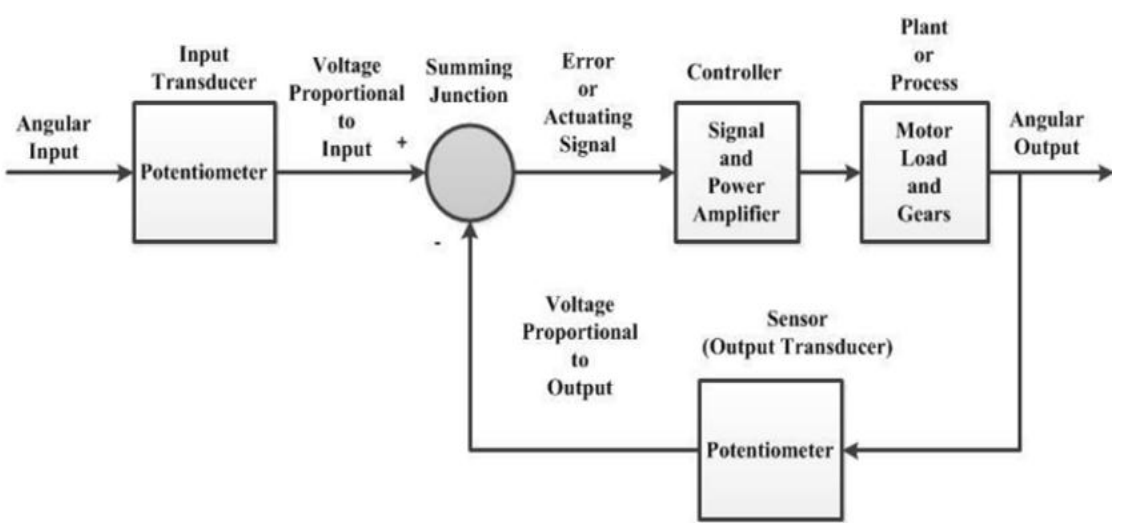

Figure 2. Block diagram of antenna-azimuth position controlling system

The process starts with the turning of input angular rotation by the potentiometer in to a voltage. Similarly, in the output region, the potentiometer converts the rotation angle to voltage, and returned back to the input with a feedback. The alteration between the input and output voltage is increasing with the effect of 
gain and signal. While mistake or error becomes zero, the motor is not receiving any voltage and will not start [8].

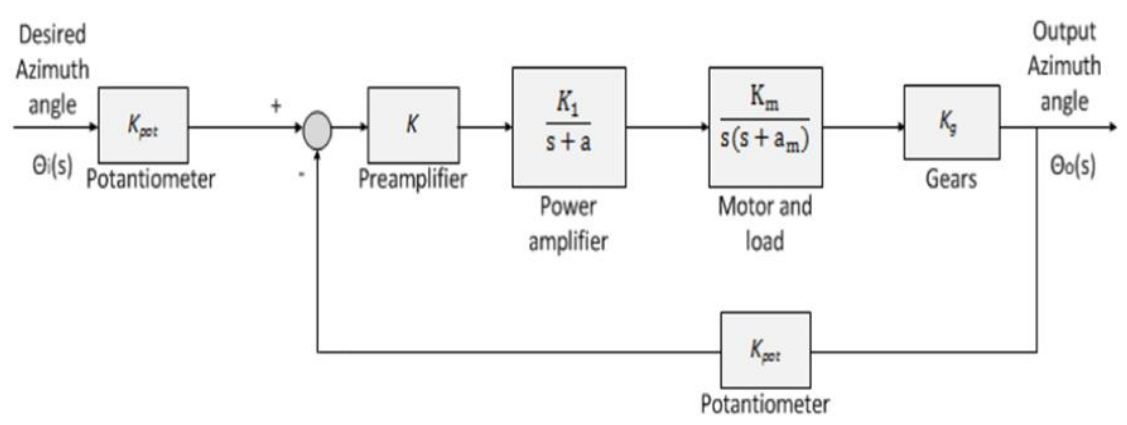

Figure 3. Block diagram in detail of antenna azimuth control system

Figure 3 describes the comprehensive block diagram of the system for controlling the position of antenna.Gears as well as the load are attached to the motor, in this system the antenna is considered as a load. The deep derivation of the motor transfer function could be found in [1], and the final model transfer function:

$$
\frac{\Theta_{m}(s)}{E_{a}(s)}=\frac{K_{t} / J_{m} R_{a}}{s\left(s+\frac{D_{m} R_{a}+K_{b} K_{t}}{J_{m} R_{a}}\right)}
$$

Where, $\mathrm{Ra}$ is the motor resistance, $\mathrm{Kt}$ and $\mathrm{Kb}$ are the back EMF and torque constant of the motor respectively.

The components of the system including (dampening and inertial) are linked to the motor by gears sets. This leads to changing of their operative values which is realized with the motor and have to be inserted within the mathematics.

$$
\mathrm{Kg}=\mathrm{N} 1 / \mathrm{N} 2=0.1
$$

In the above equation, $\mathrm{N} 1$ and $\mathrm{N} 2$ represent the gear teeth.

$$
J_{m=} J_{a}+J_{L}\left(k g^{2}\right)=0.03
$$

Where $J_{L}=$ is the load inertia at $\Theta o$. The equivalent viscous damping, $D_{m}$, at the armature is:

$$
D_{m=} D_{a}+D_{L}\left(k g^{2}\right)=0.02
$$

Where $D_{L}$ is the load viscous damping at $\Theta o$. From the problem statement, $K_{t}=0.5 \mathrm{~N}-\mathrm{m} / \mathrm{A}, \mathrm{Kb}=0.5 \mathrm{~V}-\mathrm{s} / \mathrm{rad}$, and the armature resistance $\mathrm{Ra}=8 \mathrm{ohms}$. So, So, motor and load the transfer function would be:

$$
\frac{\Theta m(s)}{\operatorname{Ea}(s)}=\frac{\frac{\mathrm{Kt}}{\mathrm{JmRa}}}{\mathrm{s}\left(\mathrm{s}+\frac{\mathrm{DmRa}+\mathrm{KbKt}}{\mathrm{JmRa}}\right)}=\frac{2.083}{\mathrm{~s}(\mathrm{~s}+1.71)}
$$

Next step of determining motor transfer function, the gear ratio need to be multiplied with equation 1 in order toget the ratio of load displacement to armature voltage:

$$
\frac{\theta 0(\mathrm{~s})}{\mathrm{Ea}(\mathrm{s})}=0.1 \frac{\theta \mathrm{m}(\mathrm{s})}{\mathrm{Ea}(\mathrm{s})}=\frac{0.2083}{\mathrm{~s}(\mathrm{~s}+1.71)}
$$

Parameters for preamplifier, power and gears of above block diagram are given in Table 1.

In Table 1, gain value " $\mathrm{K}$ " is unknown which represents the preamplifier gain. The result block diagram is shown for each transfer function in Figure 4. Consecutively, the final closed-loop system model will be 
as Equation (3):

$$
\frac{\theta \mathrm{o}(\mathrm{s})}{\theta \mathrm{i}(\mathrm{s})}=\frac{6.63 K}{s^{3}+101.71 s^{2}+171 s+6.63 K}
$$

Table 1. Parameters of Antenna Block Diagram

\begin{tabular}{cc}
\hline Parameters & Configurations \\
\hline $\mathrm{K}$ & ---- \\
$\mathrm{K}_{\mathrm{pot}}$ & 0.318 \\
$\mathrm{Ra}$ & 100 \\
$\mathrm{~K}_{1}$ & 100 \\
$\mathrm{~K}_{\mathrm{g}}$ & 0.1 \\
\hline
\end{tabular}

Routh-Herwitz criterion could be utilized in to obtain the preamplifier gain value " $\mathrm{K}$ " which makes the system reaching stability. According to this this criterion, system will could be considered as stable in term of response if the value of gain " $\mathrm{K}$ " taken in the range 0-262.3 [9]. Depending on [10], better value of " $\mathrm{K}$ " within the mentioned range is 31.6 since best response is gotten with that value.

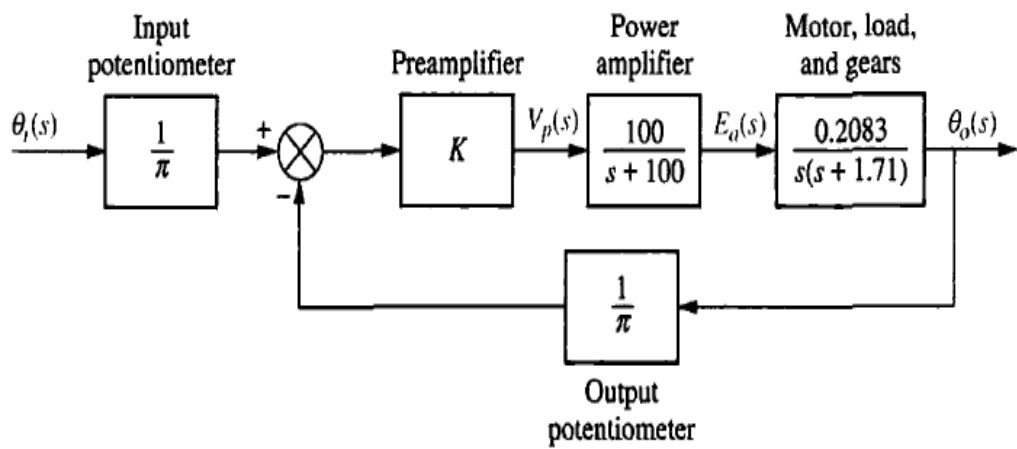

Figure 4. The related model of every subsystem of antenna azimuth control system

\section{PID CONTROLLER}

Proportional-integral-derivative (PID) controllers could be considered as a common used controller in practically manufacturing control applications [11], [12]. This controller offers simplicity, versatility, reliability, flexibility and speed, which makes this controller very popular [13]. The classic PID block diagram is represented in Figure 5:

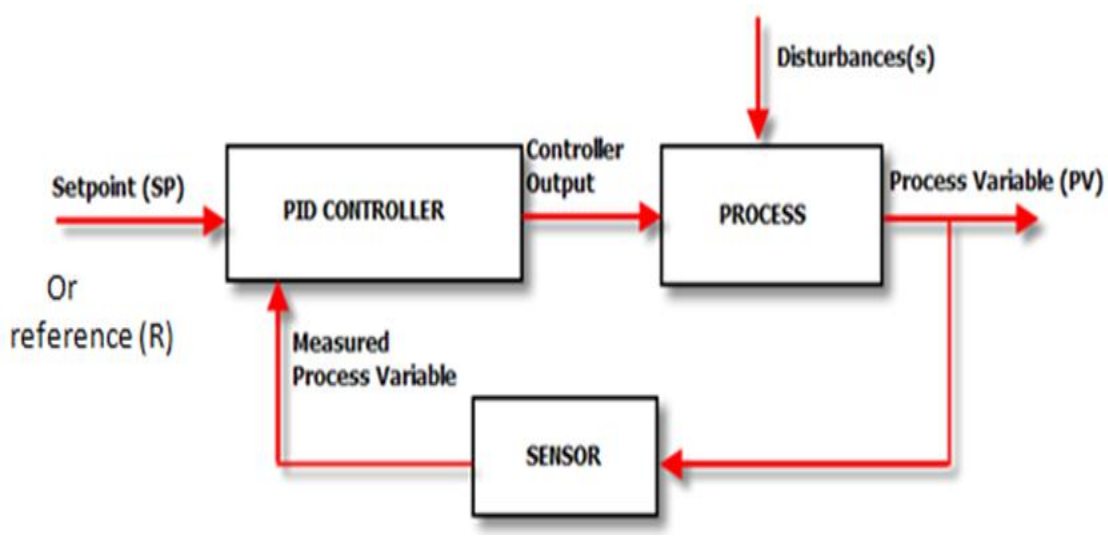

Figure 5. The classic block diagram of a process under PID 
The PID controller in parallel form [14] is represented in the following equation:

$$
U(t)=K_{p} e(t)+K_{i} \int e(t)+K_{d} \frac{d e(t)}{d t}
$$

Where $\mathrm{Kp}$ is proportional gain, $\mathrm{Ki}$ is integral gain, $\mathrm{Kd}$ is derivative gain and $\mathrm{e}(\mathrm{t})=$ error. The PID model in Frequency domain or transfer function is represented in the following equation:

$$
\frac{U(s)}{E(s)}=K_{p}+\frac{K_{i}}{s}+K_{d} s
$$

\subsection{Ziegler Nichols tuning method}

In 1942, Ziegler-Nichols introduced a rule which could be followed in order to tune PID controller and has named as Z-N tuning rule [15]. Ziegler-Nichols algorithm has the best performance with fastest rise time, settling time and was able to restore the system back to normal operating condition in a short time when subjected to disturbance compare to Cohen \& Coon controller and Hagglund-Astrom algorithm settings. Values of PID controller gain could be tuned according to zeglior tuning rule table [16]. The presented values might be optimal values and further adequate tuning is required in some case in order to gain better performance for the system. Depending on the system purpose and application, The PID-controller type is selected to be applied to any system.

\subsection{Finding the transfer function of overal system after PID control}

As mentioned earlier the overall model.

$$
\frac{\theta \mathrm{o}(\mathrm{s})}{\Theta \mathrm{i}(\mathrm{s})}=\frac{6.63 K}{s^{3}+101.71 s^{2}+171 s+6.63 K}
$$

By taken $K=31.6$ according to [10]. Assuming process transfer function, $G p(s)=(\Theta o(s)) /(\Theta i(s))$ and the controller transfer function is $\mathrm{Gc}(\mathrm{s})$, so:

$$
\begin{aligned}
& \mathrm{Gp}(\mathrm{s})=\frac{209.508}{s^{3}+101.73 s^{2}+171 s+209.506} \\
& \mathrm{Gc}(\mathrm{s})=\frac{k p\left(\text { Ti.Td.s } \mathrm{s}^{2}+\text { Tis }+1\right)}{\text { Tis }}
\end{aligned}
$$

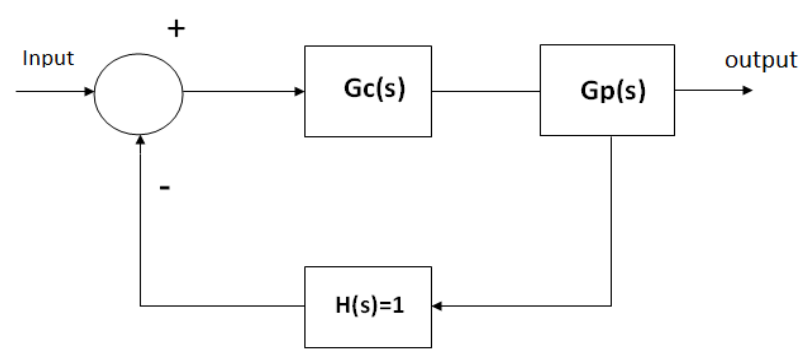

Figure 6. The closed-loop system diagram after adding controller block

Figure 6 illustrates the closed loop system diagram after adding the controller.According to figure6, the closed- loop model is going to be situated as Equation (9) below:

$$
G_{\text {close }}(s)=\frac{k p\left(T i . T d . s^{2}+T i s+1\right)}{\text { Tis }^{4}+101.72 T i s^{3} 1+(171+209.508 k p T d) T i s^{2+}(1+k p) 209.508 T i s+209.508 k p}
$$

\subsection{Design of the response the closed-loop using PID-controller}

The simulation block is shown in Figure 8 bellow. This is represented in term of input signal $(\theta \mathrm{i})$, output signal $(\theta 0)$ and the error (e-theta). PID controller is used to decrease amount of overshoot in the response. Figure 7 shows the complete system diagram after introducing PID-controller. 


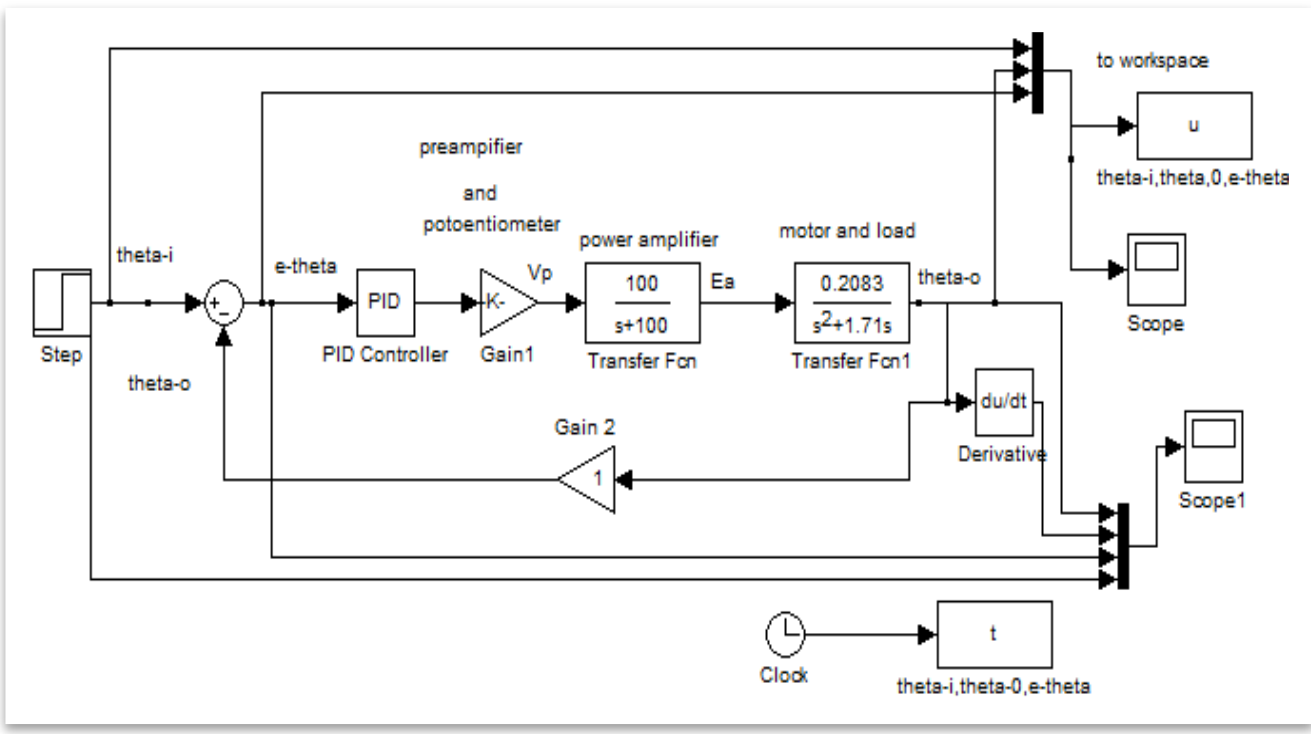

Figure 7. Closed-loop system design with PID

\subsection{Tuning of PIDcController via Zieglior-Nichols method}

Firstly, we increase the value of Kp until the system response reach instability point or it shows sustained oscillation, this value of $\mathrm{kp}$ known as $\mathrm{kc}$, which is equal to 80 in our case. Figure 8 illustrates the response when $\mathrm{kc}=82$ :

Then we found value of Tc in the graph by measuring the period from peak to peak which is equal to 0.5 in our case. Then the value of $\mathrm{Kp}, \mathrm{Ti}$ and $\mathrm{Td}$ are founded according to Ziegler table [16], by substituting each of $\mathrm{kc}$ and $\mathrm{Tc}$. We get, $\mathrm{Kp}=16.4, \mathrm{Ti}=0.15$ and $\mathrm{Td}=0.25$. Worth mentioning that the obtained values of $\mathrm{Kp}$, Ti and Td could not be considered as optimal and in order to achieve best performance for the sys-tem more tuning is needed. The PID controller type could be selected depending on the application of the system and designer goal as well. Figure 9 shows result of the system response.

Finally the acceptable response with small amount of over-shoot has been acquired from ZieglerNichols PID tuning method. More to the point, by substituting the value of $\mathrm{kp}$, Ti and Td in Equation (9), the final closed loop transfer function will be as shown in Equation (10).

$$
G_{\text {close }}(s)=\frac{234.65 s^{2}+1418.4 s+5669.4}{0.25 s^{4}+25.43 s^{3}+227.4 s^{2}+1470.78 s+5669.4}
$$

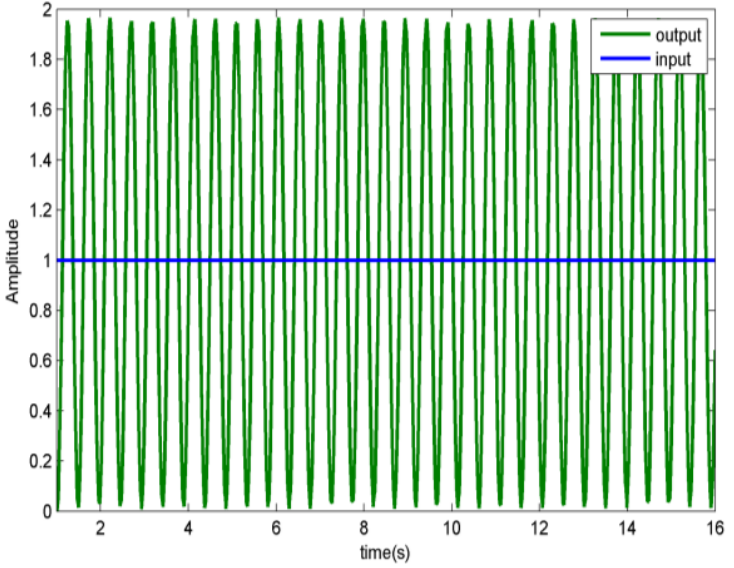

Figure 8. The response of the system with PID controller $(\mathrm{kp}=82, \mathrm{kd}=\mathrm{ki}=0)$

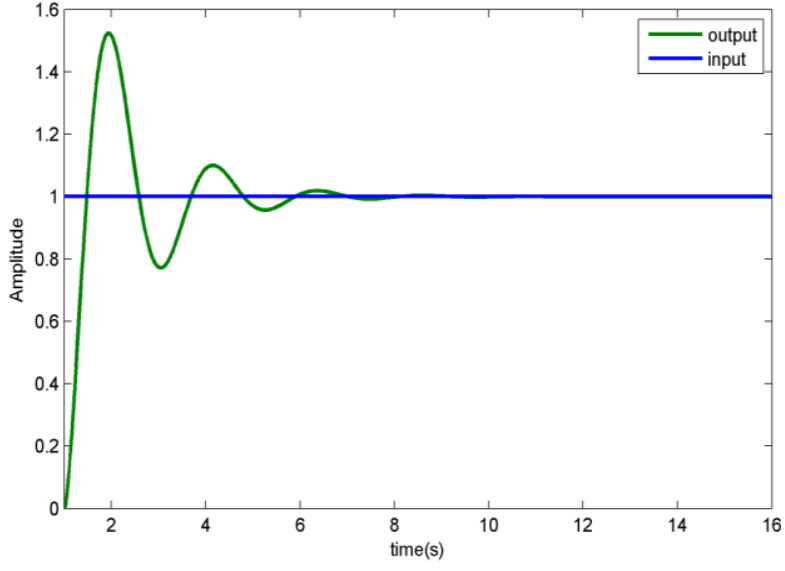

Figure 9. Closed loop system response after applying PID controller when $\mathrm{Kp}=16.4, \mathrm{Ti}=0.15$ and $\mathrm{Td}=0.25$ 


\section{DESIGN OF STATE-FEEDBACK CONTROLLER USING POLE-PLACEMENT APPROACH}

State space representation is very powerful techniques used in analyse and model varied systems, since it could be applied to nonlinearities and multiple-input, multiple-output systems. The state-feedback design technique is to create a compensator in the feedback path with the plant that has the correct additional poles and zeros to meet a desired transient response and steady-state error. The plant's characteristics may be required to change by using a closed-loop control system, in this process a controller is considered to locate the closed-loop poles at looked-for place. The mentioned method is called pole-placement technique. The state-space method using state feedback offers adequate number of parameters of the controller design to transfer all the poles of closed-loop independently of each other [17].

\subsection{Topology for pole placement}

Normally the state space equation of a plant is:

$x=A x+B u$

$y=C x+D u$

Figure 10 displays the State-space map graph of a plant.

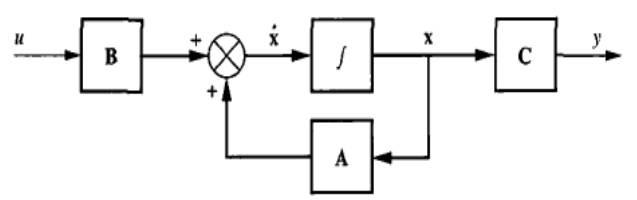

Figure 10. A plant State-space graph

In the topology of state-variable feedback, the state-variables are feedback to summing junction and then to $\mathrm{u}$ through gains meaning that each state variable connects to a gain $K_{i}$. In order to harvest obligatory closed-loop pole val-ues, $K_{i}$ could be adjusted. Figure 11 presents a plant state-variable feedback graph.

$$
\begin{aligned}
& x=A x+B u=A x+B(-\dot{K} x+r)=(A-B K) x+B r \\
& y=C x
\end{aligned}
$$

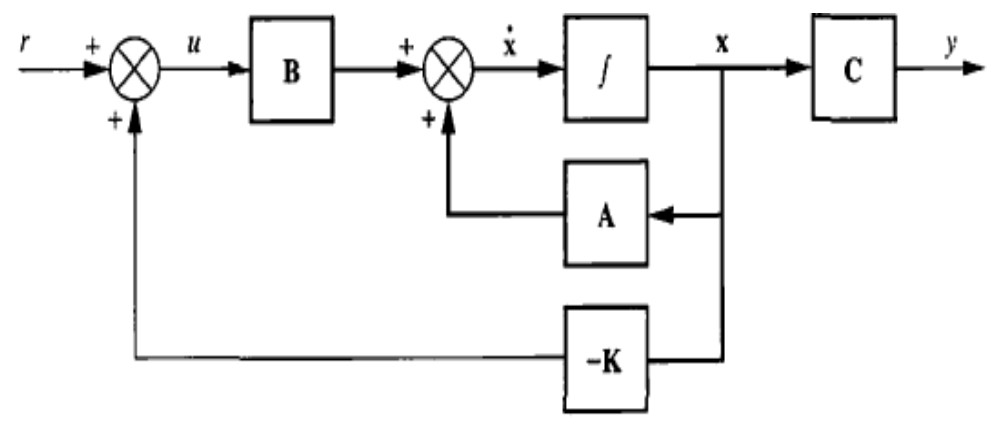

Figure 11. A plant state-variable feedback graph

\subsection{Controller design procedure}

Many steps need to be followed in order to apply pole placement methodology; these steps will be presented below.

First of all, the plant model transfer function need to be con-verted to state-space representation as illustrated in [1]. Lets the plant given as:

$$
G(s)=\frac{b_{o}}{a_{n}+a_{n-1}+. .+a_{2}+a_{1}+a_{o}}
$$

The state-space representation will be as Equation (11) and the characteristics quationwill be as Equation (12). 


$$
\begin{aligned}
& \mathrm{A}=\left[\begin{array}{ccccc}
0 & 1 & 0 & \cdots & 0 \\
0 & 0 & 1 & \cdots & 0 \\
\vdots & \vdots & \vdots & \vdots & \vdots \\
-a_{o} & -a_{1} & -a_{2} & \cdots & -a_{n-1}
\end{array}\right] ; \mathrm{B}=\left[\begin{array}{c}
0 \\
0 \\
\vdots \\
b_{0}
\end{array}\right] . \\
& \mathrm{C}=\left[\begin{array}{llll}
1 & 0 & \cdots & 0
\end{array}\right] \\
& s^{n}+a_{n-1} s^{n-1}+\cdots+a_{1} s+a_{0}=0
\end{aligned}
$$

Now form the closed-loop system by feeding back each state variable to $\mathrm{u}$, forming Equation (13):

$$
u=-k x
$$

Where, The $K_{i}$ 's are the feedback gains,

$$
K=\left[\begin{array}{llll}
k_{1} & k_{2} & \ldots & k_{n}
\end{array}\right]
$$

Using Equation (11) with Equation (14), the system matrix A-BK for the closed loop will be:

$$
\mathrm{A}-\mathrm{BK}=\left[\begin{array}{ccccc}
0 & 1 & 0 & \cdots & 0 \\
0 & 0 & 1 & \cdots & 0 \\
\vdots & \vdots & \vdots & \vdots & \vdots \\
-\left(a_{0}+b_{0} k_{1}\right) & -\left(a_{1}+b_{0} k_{2}\right) & -\left(a_{2}+b_{0} k_{3}\right) & \cdots & -\left(a_{n-1}+b_{0} k_{n}\right)
\end{array}\right]
$$

The closed loop system characteristic equation is:

$$
\begin{aligned}
& \operatorname{det}(s I-(A-B K)) \\
& =s^{n}+\left(a_{n-1}+b_{0} k_{n}\right) s^{n-1}+\left(a_{n-1}+b_{0} k_{n-1}\right) s^{n-2}+\cdots\left(a_{1}+b_{0} k_{2}\right) s+\left(a_{0}+b_{0} k_{1)}=(16)\right.
\end{aligned}
$$

And, the desired-characteristic equation is:

$$
s^{n}+d_{n-1} s^{n-1}+d_{n-2} s^{n-2}+\cdots+d_{2} 2+d_{1} s+d=0
$$

Where $d_{i}$ 's are the desired coefficients so, from the two above Equations (16) and (17), we find:

$$
\begin{aligned}
& d_{i}=a_{i}+b_{0} k_{i+1} \quad i=0,1,2, \ldots, n-1 \\
& k_{i+1}=d_{i}-a_{i} / b_{0}
\end{aligned}
$$

Now closed-loop state-space model could be determined easily and the response of it as well.

\section{CONTROLLABILITY}

The issue of system controllability has been lengthily introduced and discussed very earlier. Until now, numerous principles have been established, counting different kinds of matrix rank settings and considerable graphic materials [18], [19]. According to [20], for an nth-order plant whose state equation is:

$$
x=A \dot{x}+B u
$$

Considered as totally controllable when the matrix.

$$
\mathrm{C}_{\mathrm{M}}=\left[B A B A^{2} B \ldots A^{n-1} B\right]
$$

\section{STATE-FEEDBACK CONTROLLER DESIGN FOR ANTENNA AZIMUTH POSITION CONTROL SYSTEM}

The block diagram of the system is shown earlier in Figure 3. Depending on [10], better value for the preamplifier is 31.6 and the forward transfer function is going to as presented in Figure 12 after removing 
the existing feedback.

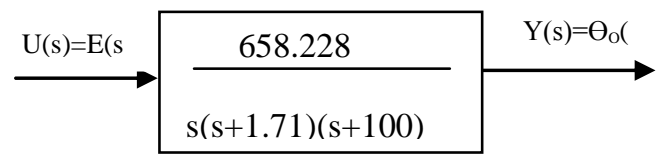

Figure 12. Antenna control system simplified block diagram with $\mathrm{k}=31.6$

First of all, it is wanted to test system controllability to see whether the system is controllable or not. Since the transfer function of the system is:

$$
G(s)=\frac{658.228}{s^{3}+101.7 s^{2}+171 s}
$$

So, the state equation and signal flow graph could be obtained and written as shown below:

$$
\begin{aligned}
& \dot{x}=\left[\begin{array}{ccc}
0 & 1 & 0 \\
0 & 0 & 1 \\
0 & -171 & -101.71
\end{array}\right] x+\left[\begin{array}{c}
0 \\
0 \\
658.228
\end{array}\right] u=A x+B u \\
& \mathrm{y}=\left[\begin{array}{lll}
1 & 0 & 0
\end{array}\right] x=\mathrm{C} x
\end{aligned}
$$

The system controllabolity could be checked as shown bellow:

$$
A=\left[\begin{array}{ccc}
0 & 1 & 0 \\
0 & 0 & 1 \\
0 & -171 & -101.71
\end{array}\right] \quad B=\left[\begin{array}{c}
0 \\
0 \\
658.228
\end{array}\right]
$$

According to Equation (20);

$$
\mathrm{C}_{\mathrm{M}}=\left[\begin{array}{lll}
B & A B & A^{2} B
\end{array}\right]=\left[\begin{array}{ccc}
0 & 0 & 658.228 \\
0 & 658.228 & -66948.37 \\
658.228 & -66948.37 & 6696812
\end{array}\right]
$$

The determinant of $\mathrm{CM}$ is $-2.8519 \mathrm{e}+008$, so the system is controllable. The rank of $\mathrm{CM}$ equals the number of linearly independent rows or columns. The rank can be found by finding the highest-order square sub matrix that is non-singular. The determinant of $\mathrm{CM}=-2.8519 \mathrm{e}+008$. Since the determinant is not zero, the $3 \times 3$ matrix is non-singular, and the rank of $\mathrm{CM}$ is 3 . We conclude that the system is controllable since the rank of CM equals the system order. Thus, the poles of the system can be placed using state-variable feedback design.

$\mathrm{A}=\left[\begin{array}{llll}0 & 1 & 0\end{array}\right.$

0001

$0-171-101.71]$

$\mathrm{B}=[0 ; 0 ; 658.228]$

$\mathrm{Cm}=\operatorname{ctrb}(\mathrm{A}, \mathrm{B})$

$\operatorname{Rank}=\operatorname{rank}(\mathrm{Cm})$

Ans $=3$

Thus the system is controllable.

In fact, the selection of the locatoions of closed-loop poles is considered as a main difficulty in designing the controllers based pole-placement technique [21]. According to [22], the eigenvalues of the state feedback can be placed in any position as well as the feedback gain could be found directly by substitution. Worth mentioning, this method does not tell the controllability condition in what way arise to the design that's why a further efficient approach is recommended.

At this time, for controller design specification and for getting better transient response, it is required to produce overshoot around $4.3 \%$ and 1.4 second settling time. $\delta=0.7$ and $w_{n}=4$. Based on that, the 8 characteristic equation for the dominant poles is:

$$
s 2+5.66 s+16.4=0
$$


Where, dominant poles location at $-2.83 \pm \mathrm{j} 2.9$. The third pole is about 10 times distant from the imaginary axis, at -40 .eventually, the closed-loop system desired characteristic equation be:

$$
\left(s^{2}+5.66 s+16.4\right)(s+40)=s^{3}+45.66 s^{2}+242.8 s+656=0
$$

And then,

$$
A-B K=\left[\begin{array}{ccc}
0 & 1 & 0 \\
0 & 0 & 1 \\
-658.22 k_{1} & -\left(171+658.22 k_{2}\right) & -\left(101.71+658.22 k_{3}\right)
\end{array}\right]
$$

In consequence, the closed loop characteristic equation is:

$$
\begin{aligned}
& \operatorname{det}[s I-(A-B K)]=s^{3}+\left(101.71+658.22 k_{3}\right) s^{2}+\left(171+658.22 k_{2}\right) s \\
& +658.22 k_{1}=0
\end{aligned}
$$

By comparing Equation (25) with Equation (26) and matching the coefficients of both of them, the $k_{i}$ 's could be evaluated as follows:

$k_{1}=0.997, k_{2}=0.1091$ and $k_{3}=-0.0852$

The direct matlab coding for the controller design and applying it to the system is:

num $=658.228$

den $=\left[\begin{array}{llll}1 & 101.71 & 171 & 0\end{array}\right]$

$\mathrm{g}=\mathrm{tf}$ (num,den)

$[\mathrm{a}, \mathrm{b}, \mathrm{c}, \mathrm{d}]=\mathrm{tf} 2 \mathrm{ss}($ num,den $)$

$\mathrm{a}=\left[\begin{array}{lllllll}0 & 1 & 0 ; 0 & 0 & 1 ; 0 & -171 & -101.71\end{array}\right]$

$\mathrm{b}=[0 ; 0 ; 658.228]$

$\mathrm{c}=\left[\begin{array}{lllllll}1 & 0 & 0 ; 0 & 1 & 0 ; 0 & 0 & 1\end{array}\right]$

$\mathrm{d}=[0 ; 0 ; 0]$

plant $=\mathrm{ss}(\mathrm{a}, \mathrm{b}, \mathrm{c}, \mathrm{d})$

$\mathrm{p}=[-40-2.83-2.9 \mathrm{j}-2.83+2.9 \mathrm{j}]$

$\mathrm{k} 1=$ place $(\mathrm{a} 2, \mathrm{~b} 2, \mathrm{p} 1)$

$\mathrm{k} 1=0.9978 \quad 0.1091 \quad-0.0852$

cl_sys=feedback(plant,k1)

step(cl_sys)

It's noted that the value of $k_{i}$ s which has been calculated earlier is the same that obtained in matlab code running

\section{RESULT AND DESCUSSION}

After the design of state-feedback controller for antenna azimuth position system, the overall system with the controller has been simulated. The response is accepted and desired since it has zero steady-state error and small value of settling time and overshoot as well, the graph is presented in Figure 13.

Furthermore, the system step response with PID controller is compared to system step response using state-feedback controller to find the performance. As a result, it has been observed that, in spite of small rise time and fast response in case of using PID controller but still the response is considered as not good, due to high overshoot and much settling time value. While, very minor overshoot, small settling time value as well as zero -steady-state error is gained after applying state-feedback controller to the system. The comparison of both cases is presented in Figure 14. Figure 15 presents the system steady error after applying both controllers. 


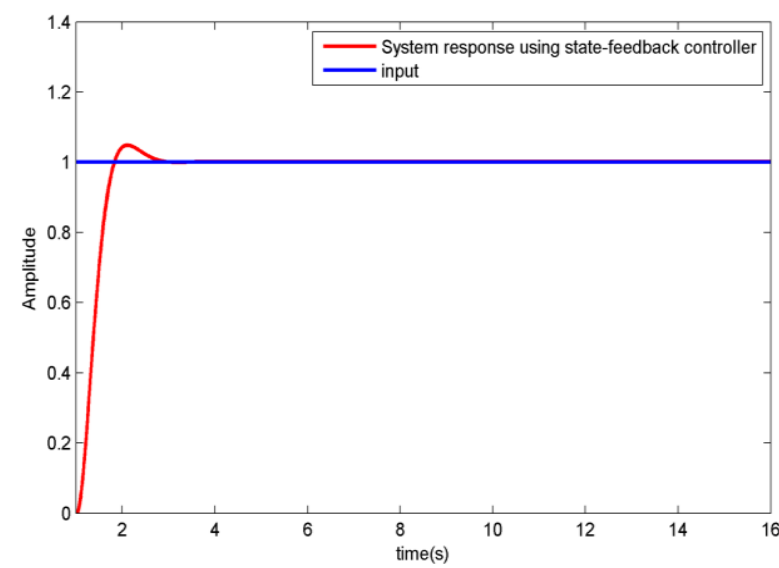

Figure 13. The system step response after applying state feedback controller

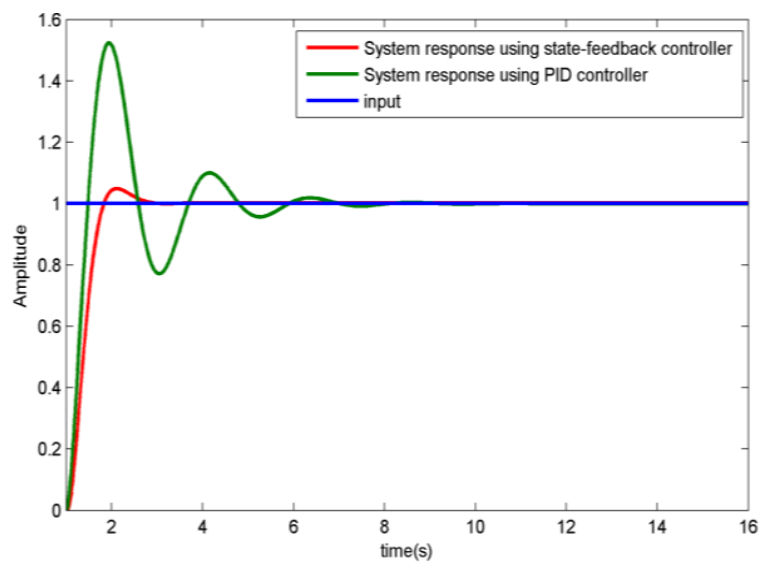

Figure 14. The system response with state-feedback controller

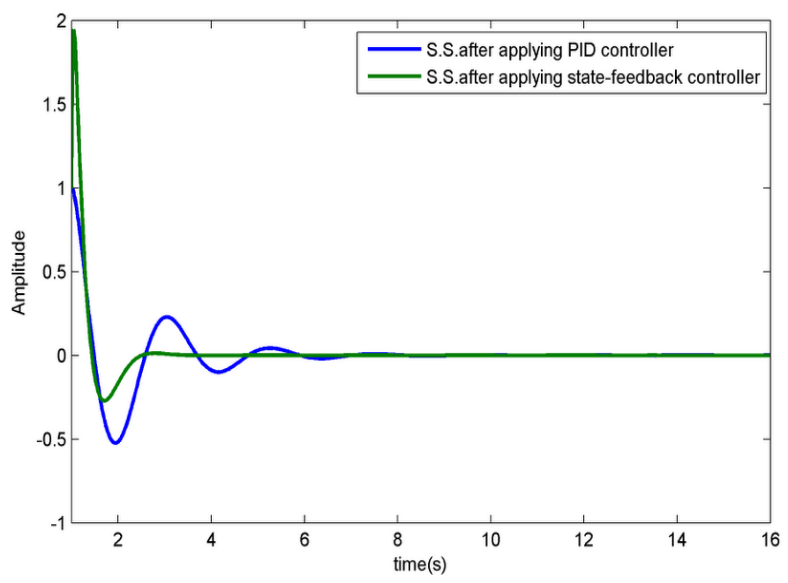

Figure 15. The system steady-state error after applying PID \& state-feedback controller

\section{CONCLUSION AND FUTURE WORK}

As a conclusion, the overall antenna azimuth position control system in this work is well described then analysed in term of modeling of each subsystem and figure out how it is operate. The transfer function is obtained for each part and overall system as well. In order to prove the result, Matlab simulink has been used. First of all, the closed-loop system response was found without applying any controller, the result indicates that the system response is unstable and it has a high overshoot. Later on, PID controller has been designed and applied to the system by following Ziegler-Nichols tuning method in order to provide ample stability and good response characteristics. The response with the existing controller is much better than without using it, since the stability and the characteristics of the response is enhanced, but still it has overshoot problem. In order to come out with a good transient response specification, a state-feedback controller using pole placement assignment is introduced and designed for the system. The result response shows a perfect response with only some overshoot percentage, little settling time as well as no steady state error is observed.

Future work: For the future study, it is suggested to design other kinds of intelligent controllers for this system like robust controllers as well as discrete PID controllers in order to reduce the disturbance and come out with more efficient and stable response. Further analysis can be done with using different range of $\mathrm{K}$ value and then the exact point of stability can be determined. Finally, it would be interesting if this system going to be implemented physically in real life.

\section{REFERENCES}

[1] N.S. Nise, "Control System Engineering", 6th Ed., John Wiley \& Sons, 2000.

[2] T.V. Hoi, N. T.Xuan and B. G. Duong, "Satellite tracking control system using Fuzzy PID controller", VNU Journal of Science: Mathematics and Physics, vol. 31, pp. 36-46,2015. 
[3] L. Xuan, J. Estrada and J. Digiacomandrea, "Antenna Azimuth Position Control System Analysis and Controller Implementation", term project, 2009.

[4] M. N.Soltani, R. Zamanabadi, and R.Wisniewski, "Reliable control of ship-mounted satellite tracking antenna", IEEE Transactions on Control Systems Technology, 2010.

[5] M. Ahmed, S.B. Mohd Noor, M.K. Hassan and A.B. Che Soh, "A Review of Strategies for Parabolic Antenna Control”, Australian Journal of Basic and Applied Sciences, vol. 8, pp. 135-148,2014.

[6] L.A. Alooa, P.K. Kihatob and S.I. Kamauc, "DC Servomotor-based Antenna Positioning Control System Design using Hybrid PID-LQR Controller", European International Journal of Science and Technology, vol. 5, pp. 17-31, 2016.

[7] H.İ. Okumus, E. Sahin and O. Akyazi, "Antenna Azimuth Position Control with Fuzzy Logic and Self-Tuning Fuzzy Logic Controllers", inElectrical and Electronics Engineering (ELECO), Nov. 8th International Conference IEEE, pp. 477-481,2013.

[8] K. Ogata, "Modern Control Engineering", Prentice-Hall Inc. USA, 5th Edition, pp. 95-96, 2010.

[9] A.R. Chishti, S.F.U.R. Bukhari, H.S. Khaliq, M.H. Khan and S.Z.H. Bukhari, "Radio Telescope Antenna Azimuth Position Control System Design And Analysis In Matlab/Simulink Using PID \& LQR Controller", The Islamia University of Bahawalpur, Pakistan, 2014.

[10] B. Temelkovski and J. Achkoski, "Modeling and Simulation of Antenna Azimuth Position Control System", International Journal of Multidisciplinary and Current Research, vol. 2, pp. 254-257, 2014.

[11] G. Franklin, F. Powell and A. Emami-Naeini, "Feedback Control of Dynamic Systems", 4 th Ed., Addison-Wesley Publishing Company, 2002.

[12] R. Babu, R. Samuel, S. Deepa and S. Jothivel, "A closed loop control of quadratic boost converter using pidcontroller”, International Journal of Engineering, vol. 27, pp. 1653-1662, 2014.

[13] M.A. Javadi Rad and A. Taheri, "Digital Controller Design Based on Time Domain for DC-DC Buck Converter", International Journal of Engineering, vol. 28, pp. 693-700, 2015.

[14] P.R.E Kumar, and V.N. Babu, "Position Control of Servo Systems using PID Controller Tuning with Soft Computing Optimization Techniques", International Journal of Engineering Research \& Technology (IJERT), vol. 3, pp. 976-980,2014.

[15] O. Ibrahim, S.A. Amuda, O.O. Mohammed and G.A. Kareem, "Performance Evaluation of three PID Controller Tuning Algorithm on a process plant", International Journal of Electrical and Computer Engineering, vol. 5, 2015.

[16] S. Anthony,Mc Cormack andR. G. Keith, "Rule-Based Autotuning Based on Frequency Domain Identification", IEEE Transactions on Control Systems Technology, vol. 6, 1998

[17] T. Ashish, "Modern control design with Matlab and simulink", Indian Institute of Technology, Kanpur, India, John Wiley \& Son, 2002.

[18] J. Ruths and D. Ruths, "Control profiles of complex networks”, Science, vol. 343, pp. 1373-1376, 2014.

[19] R.W. Shields and J.B. Pearson, "Structural controllability of multiinput linear systems", IEEE Transactions on Automatic Control, vol. 21, pp. 203-212, 1976.

[20] P.K.Sinha, "Multivariable control: An introduction", Marcel Dekker, Inc. New York, NY, USA, 1984.

[21] M.H. Al-qatamin, "An Optimal State Feedback Controller Based Neural Networks for Synchronous Generator Excitation Control System", International Journal of Electrical and Computer Engineering, vol. 3, pp. 561-567, 2015.

[22] C.T. Chen, "Linear System Theory And Design”, Oxford University Press, 1999.

\section{APPENDIX}

\begin{tabular}{clcl}
\hline Schematic parameters & & \multicolumn{2}{c}{ Parameters } \\
\hline $\mathbf{V}$ & Voltageacross Potentiometer & Kpot & Potentiometer gain \\
$\mathbf{N}$ & Turns of potentiometer & $\mathbf{K}$ & Preamplifier gain \\
$\mathbf{K}_{1}$ & Power Amplifier Gain & Power Amplifier pole \\
$\mathbf{J}_{\mathbf{L}}$ & Load inertial constant $\left[\mathrm{kg}-\mathrm{m}^{2}\right]$ & $\mathbf{K}_{\mathbf{m}}$ & Motor and load gain \\
$\mathbf{R}_{\mathbf{a}}$ & Motor Resistance [ohms] & $\mathbf{a}_{\mathbf{m}}$ & Motor and load pole \\
$\mathbf{J}_{\mathbf{a}}$ & Motor Inertial constant $\left[\mathrm{kg}-\mathrm{m}^{2}\right]$ & $\mathbf{K}_{\mathbf{g}}$ & Gear ratio \\
\cline { 2 - 3 } $\mathbf{D}_{\mathbf{a}}$ & Motor Dampening constant $[\mathrm{N}-\mathrm{m} \mathrm{s} / \mathrm{rad}]$ & & \\
$\mathbf{K}_{\mathbf{b}}$ & Back EMF constant $[\mathrm{V}-\mathrm{s} / \mathrm{rad}]$ & & \\
$\mathbf{K}_{\mathbf{t}}$ & Motor Torque constant $[\mathrm{N}-\mathrm{m} / \mathrm{A}]$ & & \\
$\mathbf{N}_{\mathbf{1}}$ & Gear teeth & & \\
$\mathbf{N}_{\mathbf{2}}$ & Gear teeth & & \\
$\mathbf{N}_{\mathbf{3}}$ & Gear teeth & & \\
$\mathbf{N}_{\mathbf{3}}$ & Gear teeth & & \\
& & & \\
\hline
\end{tabular}

Int J Elec \& Comp Eng, Vol. 8, No. 3, June 2018 : 1539 - 1550 